\title{
Diet, kidney stones and kidney failure
}

\section{Most common renal diseases are due to vascular disease, much of which is related to dietary factors}

Both kidney stones and the most common kinds of chronic kidney disease (CKD) are in part affected by what we eat. CKD is essentially a vascular disease, and therefore worsened by diabetes, high blood pressure and atherosclerosis [1,2]. Subjects who are overweight or obese are particularly prone to all of these medical illnesses. The vascular disease that affects the kidneys also affects the other organs in the body, such as the heart and brain, this vascular disease appears to be increasing over time in all ethnic groups [3], and subjects with CKD are at increased risk of death [4]. In controlled studies, Paleolithic type diets have been shown to improve blood pressure control, blood sugar control and to help subjects lose weight to a greater degree than American Diabetes Association or Mediterranean diets [5, 6, 7]. Paleolithic diets have also been shown to improve vascular tone and elasticity, which is important for vascular health [8].

\section{Common renal stones are also related to dietary factors}

In western countries, kidney stones tend to be made out of calcium, such as calcium oxalate, uric acid, or a combination of the two. Many dietary factors are important in kidney stone formation, including hydration status, urine $\mathrm{pH}$, intake of protein, fructose, calcium and table salt, and the presence or absence of metabolic syndrome $[9,10]$. Presumably due to an increasingly warm climate, the presence of kidney stones is now found at higher latitudes than previously, and the combination of kidney stones and CKD has been increasingly described in hot climates in agricultural workers with inadequate intake of water during the daytime hours [11].

The presence of kidney stones increases with increasing free fructose intake (e.g., as in fructose corn syrup), and is thought to be due to increased uric acid production from the AMP released during the first step of fructose metabolism to fructose-1-phosphate [12]. Obesity and having a high waist-to-hip ratio is also associated with an increased risk for kidney stones [13].

Subjects at risk for calcium stones appear to have an increased propensity to absorb calcium from the gut compared to subjects without kidney stones [14]. In a low calcium environment, such a factor would help improve calcium balance, but would be a hindrance in a high calcium 
environment. Calcium stone formers then excrete more calcium in the urine than non-stone formers [15]. High salt intake also increase urine calcium excretion and adds to the acid load due to the lack of fruits and vegetables in typical western diets [15]. The combination of all of these factors (high salt, acid and calcium) not only make calcium kidney stones more likely to form, but predispose to damage to the blood vessels and direct damage to the kidneys. We are therefore now increasingly recognizing a greater proportion of people with CKD related to having kidney stones [16].

\section{Paleolithic type diets may help}

Inasmuch as Paleolithic type diets lower salt intake, tend to lower calcium intake, and lower diet acid production, they would help decrease the probability of developing kidney stones. Low salt intakes also generally improve blood pressures, especially in people with metabolic syndrome, who also tend to have high blood sugar and high lipid levels [17]. Therefore, Paleolithic type diets might be particularly helpful in those people most predisposed to developing calcium or uric kidney stones, and help those predisposed to developing progressive kidney disease from hypertensive, diabetic, atherosclerotic vascular disease. 


\section{References}

1. http://www.globalsherpa.org/urban-design-health-obesity

2. https://www.usrds.org/: US Renal Data System CKD 2010, NHANES 1999-2006 participants age 20 \& older.

3. http://kidney.niddk.nih.gov/kudiseases/pubs/kustats/\#3

4. https://www.usrds.org/: US Renal Data System CKD 2005; Point prevalent Medicare patients age 66 \& older. Adj: age/race/hospitalization/comorbidity; ref: 2005 cohort.

5. Lindeberg S, Jönsson T, Granfeldt $Y$ et al. A Palaeolithic diet improves glucose tolerance more than a Mediterranean-like diet in individuals with ischaemic heart disease. Diabetologia 50:1795-807, 2007.

6. Jönsson T, Granfeldt Y, Ahren B et al. Beneficial effects of a Paleolithic diet on cardiovascular risk factors in type 2 diabetes: a randomized cross-over pilot study. Cardiovasc Diabetol 8:35-48, 2009.

7. Masharani U, Sherchan P, Schloetter M et al. Metabolic and physiologic effects from consuming a hunter-gatherer (Paleolithic)-type diet in type 2 diabetes. Eur J Clin Nutr. 69:944-8, 2015.

8. Frassetto L A, Schloetter M, Mietus-Synder M, Morris RC Jr., Sebastian A. Metabolic and physiologic improvements from consuming a paleolithic, hunter-gatherer type diet. Eur J Clin Nutr. 63:947-55, 2009.

9. Acar B, Inci Arikan F, Emeksiz S, Dallar Y. Risk factors for nephrolithiasis in children. World J Urol. 26(6):627-30, 2008.

10. Pietrow PK, Karellas ME. Medical management of common urinary calculi. Am Fam Phys. 74(1):86-94, 2006.

11. http://www.pnas.org/content/105/28/9449/F4.expansion.html 
12. Taylor EN, Curhan GC. Fructose consumption and the risk of kidney stones. Kidney Int. 73:207-12, 2008.

13. Taylor EN; Stampfer MJ, Curhan GC. Obesity, weight gain, and the risk of kidney stones. J Am Med Assoc. 293(4):455-462, 2005. doi:10.1001/jama.293.4.455

14. Sorensen MD, Eisner BH, Stone KL et al. Impact of calcium intake and intestinal calcium absorption on kidney stones in older women: the study of osteoporotic fractures. J Urol. 187:1287-92, 2012.

15. Lemann J, Jr. Chap 7: Urinary calcium excretion and net acid excretion: effects of dietary protein, carbohydrate and calories, in Urolithiasis And Related Clinical Research, Schwille PO Ed. Plenum Press NY1984

16. Rule AD, Bergstralh EJ, Joseph Melton L III, Li X, Weaver AL, LieskeJ. Kidney stones and the risk for chronic kidney disease. Clin J Am Soc Neph. 4(4): 804-11, 2009.

17. Hoffmann IS, Alfieri AB, Cubeddu LX. Effects of lifestyle changes and metformin on salt sensitivity and nitric oxide metabolism in obese salt-sensitive Hispanics. J Human Hypertens. 21:571-8, 2007; doi:10.1038/sj.jhh.1002182. 